\title{
Impact of Regularly Supervised Training of Pranayama and Omkar Meditation on the Cardio-Respiratory Parameters and Short-Term Memory of Persons with Special Needs
}

\author{
Kunal*, Subbalakshmi Narasajjana Krishnadasa, Pai Sheila R., Rashmi Kaup Shiva, Nayanatara Arunkumar, Vino- \\ dini Nithyananda Anantharaya, Pratik Kumar Chatterjee
}

\section{Kunal*, Subbalakshmi Narasajjana Krishnadasa, Pai Sheila R., Rashmi Kaup Shiva, Nayanatara Arunku- mar, Vinodini Nithyananda Anantharaya, Pratik Ku- mar Chatterjee}

Department of Physiology, Kasturba Medical College (KMC), Mangalore, Manipal Academy of Higher Education (MAHE), Karnataka, INDIA.

Correspondence

Dr. Kunal

Department of Physiology, Kasturba Medical College (KMC) Mangalore, Manipal Academy of Higher Education (MAHE), Karnataka, INDIA

Phone No: (+91) 8792873242

Email Id: kunal.kmc@manipal.edu

History

- Submission Date: 20-11-2017

- Review completed: 10-12-2017;

- Accepted Date: 19-12-2017

DOI : 10.5530/pj.2018.2.61

Article Available online

http://www.phcogj.com/v10/i2

Copyright

(C) 2018 Phcog.Net. This is an openaccess article distributed under the terms of the Creative Commons Attribution 4.0 International license.

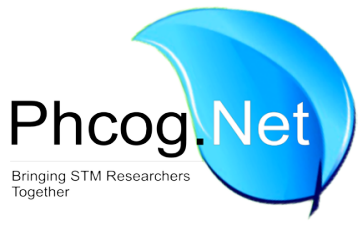

\begin{abstract}
Background: Yogic practices are known to affect the cardiac, respiratory and mental status of people. Objective: To investigate if the regularly supervised training of pranayama and meditation affects the basic cardio-respiratory parameters and short-term-memory (STM) of mentally challenged young adults. Material and methods: 80 mentally challenged young adults attending a special school were randomly divided into the control group and Yoga group. Yoga group performed Naadishodhan, Kapalbhati pranayama and Aum Chanting under total supervision for 30 min daily for 3 weeks, except on Sundays. Control group was involved with the regular school curriculum. The parameters were measured twice, before (baseline) and after (follow-up) the study period. STM was evaluated under two subcategories, first by the ability to repeat the numbers in reverse order and second, repeating the words in the same order. Respiratory rate, pulse, systolic and diastolic blood pressures were measured as cardio-respiratory parameters. Results: Both groups had similar baseline scores. At follow-up, highly significant improvements were observed in Yoga-group as compared to control. In the Yoga-group scores of both the sub-categories of STM were higher, respiratory-rate and heart-rate were lower but was within normal range. However, both systolic and diastolic blood pressures of Yoga group showed no changes as compared to control. Conclusion: The pranayama and meditation has beneficial influences on heart rate, breathing rate and STM of mentally-challenged people.

Key words: Pranayama, Mental retardation, Short term memory, Meditation, Yoga.
\end{abstract}

\section{INTRODUCTION}

During $19^{\text {th }}$ century brain used to be viewed in terms of coarse simple matter which does not change much after the childhood. Esquirol described the mental retardation (MR) as a disorder of development instead of a disease, which onset during childhood or adolescence. Now the brain is proved to be a continually changing organ, not only in its function but also in its structures. MR is established as a functioning disorder which includes abnormal intellectual functioning along with commensurate deficits in adaptive functioning. ${ }^{1}$

Yogic practices are known to affect the cardiac, respiratory and mental status of people. It opens up the possibilities that the persons with special needs can be trained and helped at any stage of their life to be able to lead a near normal social and family life.

Kapalabhati Pranayama involves forceful exhalation and effortless inspiration. It stimulates the abdominal organs, and improves autonomic balance. It promotes elimination of $\mathrm{CO} 2$ through the lungs which "quiets" the respiratory centers. ${ }^{2}$ It increases the blood $\mathrm{O} 2$ levels, which revitalize the neurons and other cells and activate the brain cells. It also probably revitalizes the entire brain and stimulates the inactive centers accountable for subtle perception, and thus, signifies its name "Shining Skull". The cognitive domains such as, attention, memory retention capacity and visuo-motor speed was improved after the pranayama practice. ${ }^{4}$

Nadishodhana Pranayama has absolute influence on cognition; are responsible for sustained attention and thus improving the higher functions of brain..$^{5,6}$ Unilateral forced nostril breathing may cause contralateral hemisphere dominance, left nostril breathing is reported to improve the spatial skills while right nostril breathing improved the verbal skills. ${ }^{7,8,9}$

"AUM" chanting reduces the physiological alertness, augments the sensitivity and synchronicity for sensory transmission. ${ }^{10}$ 'OM' chanting significantly deactivated orbito-frontal, anterior cingulate, parahippocampal gyrus thalami and hippocampus. ${ }^{11}$
Cite this article: Kunal, Subbalakshmi NK, Sheila PR, Shiva RK, Arunkumar N, Pai V, Chatterjee PK. Impact of Regularly Supervised Training of Pranayama and Omkar Meditation on the CardioRespiratory Parameters and Short-Term Memory of Persons with Special Needs. Pharmacog J. 2018;10(2):366-70 
Meditation is an altered state of consciousness known to calm the mind, slow the breath and relax the muscles in which the body is under a hypometabolic state but the brain remains consciously awake, and the person shows heightened state of consciousness. ${ }^{12}$ It is reported to bring improvements in some specific psychiatric disorders. ${ }^{13}$

\section{Aims and Objectives}

To investigate the impact of yogic practices (Nadishodhana, Kapalabhati Pranayama, 'AUM' chanting and meditation), among mentally retarded children attending a 'special school' on: 1) Resting respiratory rate; 2) Resting heart rate; 3) Blood pressure and 4) Short-Term Memory.

\section{Materials and Methods}

This study was designed as a randomized control trial of "Integrated Yogic Practice"on mentally challenged children attending St. Agnes Special School, Mangalore. Ethical committee approval from the institution and written approval and consent of the principal of this special school was obtained prior the conduct of the study.

\section{Study subjects}

Study population comprised of clinically diagnosed 80 mentally retarded children having willingness to participate in this investigation and attending the same "special school".

Inclusion criteria: clinically diagnosed mentally challenged children of either sex of chronological age between 12 to 25 years. They were unselected with regard to severity and types of mental retardation.

\section{Exclusion criteria}

Children with severe mental retardation, who were not at all able to follow the instructions;

Children with cerebral palsy

Severe sensory deficit

Severe hyperkinetic syndrome

Physically handicapped

\section{Study group}

40 mentally challenged children who performed Nadishodhana pranayama Kapalabhati and Aum Chanting under total supervision for 30 min daily for 3 weeks, except on Sundays.

\section{Control group}

Consisted of equal number of children, matched for chronological age, sex, waist-hip ratio, BMI, mental ability and environmental background to that of the study group. They did not do yogic practices; instead, they were following their prevalent school routine.

\section{Parameters studied}

The Respiratory rate, Heart rate, Blood pressure and Short-Term Memory (STM) Tests were measured twice, before (baseline) and after (follow-up) the intervention to assess the effect of yogic practice on respiratory and cardiovascular system. These parameters were recorded manually.

\section{Respiratory rate}

Respiratory rate was recorded by counting breaths per min. Three readings were taken within the span of one $h$ and the mean of the three was taken as the final reading for the analysis.

\section{Heart rate}

The recording of the heart rate was done by counting the pulse for one min at radial artery. Three readings were taken within the span of one $h$ and the mean of the three was taken as final reading for the analysis.

\section{Blood pressure}

Manual recording of blood pressure was done with the help of a sphygmomanometer. Both palpatory and auscultatory methods were used to take the readings of systolic and diastolic blood pressure.

\section{Short-Term Memory (STM)}

Tests were done according to the guidelines provided by WoodcockJohnson III Tests of Cognitive Abilities. ${ }^{4,5}$ STM was evaluated under two subcategories, first by the ability to repeat the numbers in reverse order and second, repeating the words in the same order.

\section{Numbers Reversed}

Subjects were asked to listen to a set of numbers and attempt to repeat in reverse sequence. E.g.
A) $2,5,8,3$
B) $6,3,1,9$
C) $3,7,6,5$
D) $5,2,8,4$
E) $4,3,9,5$
F) $5,3,7,2$
G) $5,8,3,7$
H) $4,9,6,3$
I) $6,1,4,9$

J) $3,7,2,6$

\section{Memory for Words}

Subjects were asked to repeat a list of unrelated words in correct sequence. E.g.

A) Ram, Cat, Ball, Fan

B) Goat, Ink, Long, Nest

C) Milk, Apple, Dog, Finger

D) Road, Rice, Cap, Finger, Pen

E) Penal, Artery, Tongue, Student

F) Shave, Monkey, Teacher, Cricket

G) Highlight, Tremor, Creature, Squash

H) Anonymous, Secretary, Complex, Senator

\section{Statistical analysis}

Data of 40 subjects in the study group and 36 in the control group was analyzed (follow-up data of 4 subjects in control group could not be collected) employing the following statistical tests:

Chi-Square test was applied to the data in frequency and the data, which could be reduced to proportions.

Unpaired t-test was applied to unpaired data of independent observation made in two separate groups.

Paired t-test, was applied to paired data of independent observations of a single sample only.

Statistical analysis was done using SPSS version 7.5. P value less than 0.05 considered significant.

\section{RESULTS}

At baseline, both the groups were comparable in their respiratory rate, heart rate, blood pressures and the scores of both the categories of STM. The mean respiratory rate $(22.10 \pm 4.74)$ found towards high normal in both the groups, while, the mean heart rate $(78.70 \pm 6.33)$ was normal (Table 1). 
Table 1: Baseline comparisons of various parameters between the control and the study groups

\begin{tabular}{|c|c|c|c|c|}
\hline \multirow[t]{2}{*}{ Parameters } & $\begin{array}{l}\text { Control } \\
\text { group }\end{array}$ & $\begin{array}{l}\text { Study } \\
\text { group }\end{array}$ & \multirow{2}{*}{$t$-value } & \multirow{2}{*}{$P$ value } \\
\hline & (Mean \pm SD) & $\begin{array}{l}\text { (Mean } \pm \\
\text { SD) }\end{array}$ & & \\
\hline $\begin{array}{l}\text { Respiratory rate (breaths/ } \\
\text { minute) }\end{array}$ & $22.68 \pm 4.23$ & $22.10 \pm 4.74$ & 0.56 & $0.58 \mathrm{~ns}$ \\
\hline Heart rate (beats/minute) & $\begin{array}{c}82.01 \pm \\
13.65\end{array}$ & $78.70 \pm 6.33$ & 1.38 & $0.17 \mathrm{~ns}$ \\
\hline $\begin{array}{l}\text { Systolic blood pressure } \\
\qquad(\mathrm{mmHg})\end{array}$ & $\begin{array}{c}100.67 \pm \\
13.05\end{array}$ & $\begin{array}{c}102.30 \pm \\
12.87\end{array}$ & 0.55 & $0.58 \mathrm{~ns}$ \\
\hline $\begin{array}{l}\text { Diastolic blood pressure } \\
\qquad(\mathrm{mmHg})\end{array}$ & $67.56 \pm 9.54$ & $68.55 \pm 8.60$ & 0.48 & $0.63 \mathrm{~ns}$ \\
\hline Numbers Reversed & $2.00 \pm 3.56$ & $1.75 \pm 3.31$ & 0.32 & $0.75 \mathrm{~ns}$ \\
\hline Memory For Words & $7.58 \pm 2.33$ & $6.93 \pm 2.15$ & 1.3 & $0.2 \mathrm{~ns}$ \\
\hline
\end{tabular}

${ }^{* *} \mathrm{p}$ value $\leq 0.005$ is highly significant; $\mathrm{ns}=$ non-significance

Table 2: comparison of cardio-respiratory parameters among the control and study group at the end of 3 weeks

\begin{tabular}{ccccc}
\hline Parameters & $\begin{array}{c}\text { Control } \\
\text { group }\end{array}$ & Study group & & \\
\cline { 2 - 3 } & (Mean \pm SD) & (Mean \pm SD) & & \\
\hline $\begin{array}{c}\text { Respiratory rate } \\
\text { (breaths/minute) }\end{array}$ & $21.19 \pm 4.06$ & $18.07 \pm 3.29$ & 3.65 & $0.001^{* *}$ \\
$\begin{array}{c}\text { Heart rate (beats/ } \\
\text { minute) }\end{array}$ & $80.97 \pm 12.97$ & $73.60 \pm 2.27$ & 3.54 & $0.001^{* *}$ \\
$\begin{array}{c}\text { Systolic blood } \\
\text { pressure (mmHg) }\end{array}$ & $102.44 \pm$ & $103.55 \pm$ & 0.40 & $0.69 \mathrm{~ns}$ \\
$\begin{array}{c}\text { Diastolic blood } \\
\text { pressure (mmHg) }\end{array}$ & $68.56 \pm 8.56$ & $69.65 \pm 8.11$ & 0.57 & $0.57 \mathrm{~ns}$ \\
\hline
\end{tabular}

${ }^{\star *} \mathrm{p}$ value $\leq 0.005$ is highly significant; $\mathrm{ns}=$ non-significance
After 3 weeks of yoga practice, highly significant decrease in the mean respiratory rate and in the mean heart rate in the study group was observed as compared to the control group ( $\mathrm{p}$ value $>0.001$; Table 2 ).

Both Systolic and Diastolic Blood pressures were found to be raised, but, change was non-significant in the study group as compared to the control group ( $\mathrm{p}$ value $>0.001$; Table 2 )

Among the two tasks of STM, "memory for words" showed improvement only in the group practicing pranayama and meditation (Table 3 \& 4). Scores of "number reversed" were higher in both, study and control, groups at the follow-up (Table $3 \& 4$ ). Nevertheless, Scores of both subcategories, namely, number reversed and memory for words and of STM as whole were significantly higher in the study group as compared to the control group (Bar-Diagram 1).

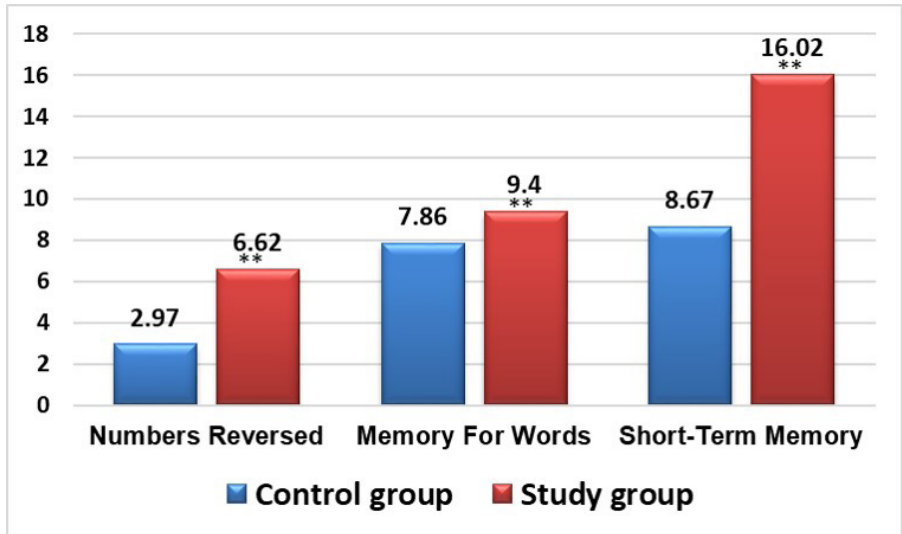

${ }^{* *} \mathrm{p}$ value $\leq 0.005$ is highly significant;

Bar-Diagram 1: Comparison of follow up scores of short-term memory between study and control group.

Table 3: Comparison between the baseline score and the follow up score of Short term memory test response in study group

\begin{tabular}{cccccc}
\hline Parameters & Baseline & Follow-up & $\begin{array}{c}\text { Mean } \\
\text { difference }\end{array}$ & \multirow{2}{*}{$t$-value } & $p$-value \\
\cline { 2 - 4 } & (Mean \pm SD) & (Mean \pm SD) & (Mean \pm SD) & & \\
\hline Numbers Reversed & $1.75 \pm 3.31$ & $6.62 \pm 3.78$ & $-4.87 \pm 3.88$ & 7.938 & $<0.001^{* *}$ \\
Memory For Words & $6.93 \pm 2.15$ & $9.40 \pm 2.14$ & $-2.47 \pm 2.44$ & 6.418 & $<0.001^{* *}$ \\
\hline
\end{tabular}

${ }^{* *} \mathrm{p}$ value $\leq 0.005$ is highly significant

Table 4: Comparison between the baseline score and the follow up score of short-term memory test response in control group

\begin{tabular}{cccccc}
\hline Parameters & Baseline & Follow-up & Mean difference & & \\
& & & & & \\
& (Mean \pm SD $)$ & (Mean \pm SD $)$ & (Mean \pm SD $)$ & & \\
& & & & & \\
\hline Numbers Reversed & $2.00 \pm 3.56$ & $2.97 \pm 4.14$ & $-0.97 \pm 1.93$ & 3.016 & $0.005^{* *}$ \\
& & & & \\
Memory For Words & $7.58 \pm 2.33$ & $7.86 \pm 2.28$ & $-0.28 \pm 2.16$ & 0.777 & $0.44 \mathrm{~ns}$ \\
\hline
\end{tabular}

${ }^{* *} \mathrm{p}$ value $\leq 0.005$ is highly significant; $\mathrm{ns}=$ non-significant 


\section{CONCLUSION AND DISCUSSION}

To the best of my knowledge, no previous study is available for comparison, investigating the effects of pranayama and meditation on "specific" cognitive abilities in mentally retarded individuals. However, one of the study reported the efficacy of Yoga as an effective therapeutic tool in the management of mentally retarded children. ${ }^{15}$

The results of the present study demonstrate the beneficial effects of pranayama and meditation on respiratory, cardiovascular and STM in mentally challenged children attending special school.

The decline in respiratory rate, suggests that daily practice of pranayama might modify the basic activity of the bulbo-pontine complex in such a way that it gets adjusted to the slower pattern of breathing than its basal rhythm. The lower respiratory rate found in this study is in agreement with the previous studies done on normal population investigating the effect yogic practice on respiratory rate.

Decline in resting heart rate suggests that the yogic practices strengthen the parasympathetic dominance. Several studies have documented decline in heart rate following yoga practice.

Number reversing ability tests the short-term (working) memory, mainly a function of pre-frontal cortex, lasts for seconds to hours, during which processing in the hippocampus and amygdala lays down long-term changes in synaptic strength. A possible explanation for STM is pre-synaptic facilitation or inhibition. Working memory is a form of STM that keeps information available, for very short periods, while the individual plans action based on it.

In this study, two tasks were given to assess the short term memory of the mentally challenged subjects. Among the two tasks, the "memory for words" showed improvement only in pranayama and meditation doing group (Table $3 \& 4$ ) and the significantly higher follow-up scores of both subcategories of STM in study group shows that yogic practices may enhance the presynaptic facilitation or inhibition involved in the processing of Short Term Memory.

The cognitive functions have overlapping representation in brain. Many of them are interrelated and interdependent. Prefrontal areas are essential to carry out logical and reasoning processes. It stores "working memories" on a short-term basis. The neural circuitry for word formation is stored in the Broca's area, in frontal cortex. For the comprehension of language somatic, visual and auditory association areas communicate with Wernicke's area in temporal cortex. Nearly all functions of higher intellectual ability, as the ability to solve logical problems or the ability to read, are dependent on the language or verbal comprehension. with the help of Wernicke's area, angular gyrus interprets the written words, names are learned through auditory input, and objects' physical natures are learned through visual input. ${ }^{16,17}$

Thus we believe that the composite practice of pranayama and meditation may cause better functioning of various areas involved in higher functions. Pranayama and meditation have been found to be beneficial in the treatment of various central nervous system ailments related to higher mental functions, such as, depression, anxiety, schizophrenia, epilepsy, and autonomic nervous system imbalances. Thus it appears that through various interrelated and integrated mechanisms, pranayama and meditation exerts a profound influence, not only on the nervous system but also on the metabolic functions of the body.

\section{ACKNOWLEDGMENT}

I would also like to convey my sincere gratitude and regards tothe principal and all the staffs and students of St. Agnes Special School for all their assistance and co-operation, without which this work would have been impossible to complete.

\section{CONFLICT OF INTEREST}

It was self-funded research work and none of the author possess any financial or personal relationships with organizations or people that could inappropriately sway our work.

\section{ABBREVIATIONS USED}

STM: Short-term-memory; MR: Mental retardation.

\section{REFERENCES}

1. Kaplan, Sadock. Mental Retardation. In: Comprehensive Textbook of Psychiatry. 7th Ed. New York: Lippincott Williams and Wilkins. 2000.

2. Desai B, Gharote M. Effect of Kapalabhati on blood urea, creatinine and tyrosine. Act Nerv Super (Praha). 1990;32(2):95-108.

3. Muktibodhananda, Pradipika HY. (Yoga Publication Trust, Munger, Bihar). 2001;187: 220-2.

4. Sharma VK, Rajajeyakumar M, Velkumary S, Subramanian SK, Bhavanani AB, Madanmohan SA, et al. Effect of fast and slow pranayama practice on cognitive functions in healthy volunteers. J Clin Diagn Res. 2014;8(1):10-3.

5. Telles S, Singh N, Puthige R. Changes in P300 following alternate nostril Yoga breathing and breath awareness. BioPsychoSocial medicine. 2013;7(1):11.

6. Subbalakshmi NK, Saxena SK, Urmimala D, Souza Urban JA. Immediate effect of 'Nadi-shodhana pranayama'. On some selected parameters of cardiovascular, pulmonary, and higher functions of brain. Thai journal of physiological sciences. 2005;18(2):10-6.

7. Werntz D, Bickford RG, Bloom FE, Shannahoff-Khalsa D. Alternating cerebral hemispheric activity and the lateralization of autonomic nervous function, Hum Neurobiol. 1983;2(1):39-43.

8. Werntz D, Bickford RG, Shannahoff-Khalsa D. Selective hemispheric stimulation by unilateral forced nostril breathing, Hum Neurobiol. 1987;6(3):165-71.

9. Jella SA, Shannahoff-Khalsa DS. The effects of unilateral forced nostril breathing on cognitive performance. Int J Neurosci. 1993;73(1-2):61-8.

10. Kumar S, Nagendra HR, Manjunath NK, Naveen KV, Telles S. Meditation on OM: Relevance from ancient texts and contemporary science. Int $\mathrm{J}$ Yoga. 2010;3(1):2-5.

11. Kalyani BG, Venkatasubramanian G, Arasappa R, Rao NP, Kalmady SV, Behere RV, et al. Neurohemodynamic correlates of ' $O M^{\prime}$ ' chanting: A pilot functional magnetic resonance imaging study. International journal of yoga. 2011;4(1):3

12. Young JDE, Taylor E. Meditation as a voluntary hypometabolic state of biological estivation. News in Physiological Sciences. 1998;13(3):149-53.

13. Shannahoff-Khalsa DS. An introduction to kundalini Yoga meditation techniques that are specific for the treatment of psychiatric disorders. The Journal of Alter native and Complementary Medicine. 2004;10(1):91-101.

14. Mather N, Woodcock RW. Woodcock-Johnson III Tests of Cognitive Abilities Examiner's Manual Standard and Extended Batteries. Itasca, IL: The Riverside Publishing Company; 2001.

15. Uma K, Nagendra HR, Nagarathna R, Vaidehi S, Seethalakshmi R. The integrated approach of yoga: A therapeutic tool for mentally retarded children: A one-year controlled study. J Ment Defic Res. 1989;33(5):415-21.

16. Guyton AC. The Nervous System: C. Motor and Integrative Neurophysiology: Cerebral Cortex, Intellectual Functions of the Brain, Learning and Memory in: Text Book of Medical Physiology, 11th ed. Philadelphia: Elsaviour and Saunders. 2006;714-28.

17. Ganong WF. Central and Pheripheral Neurophysiology: Learning, Memory, Language and Speech, In: Review of Medical Physiology, 23rd Ed. New Delhi: The Mc Graw Hill. 


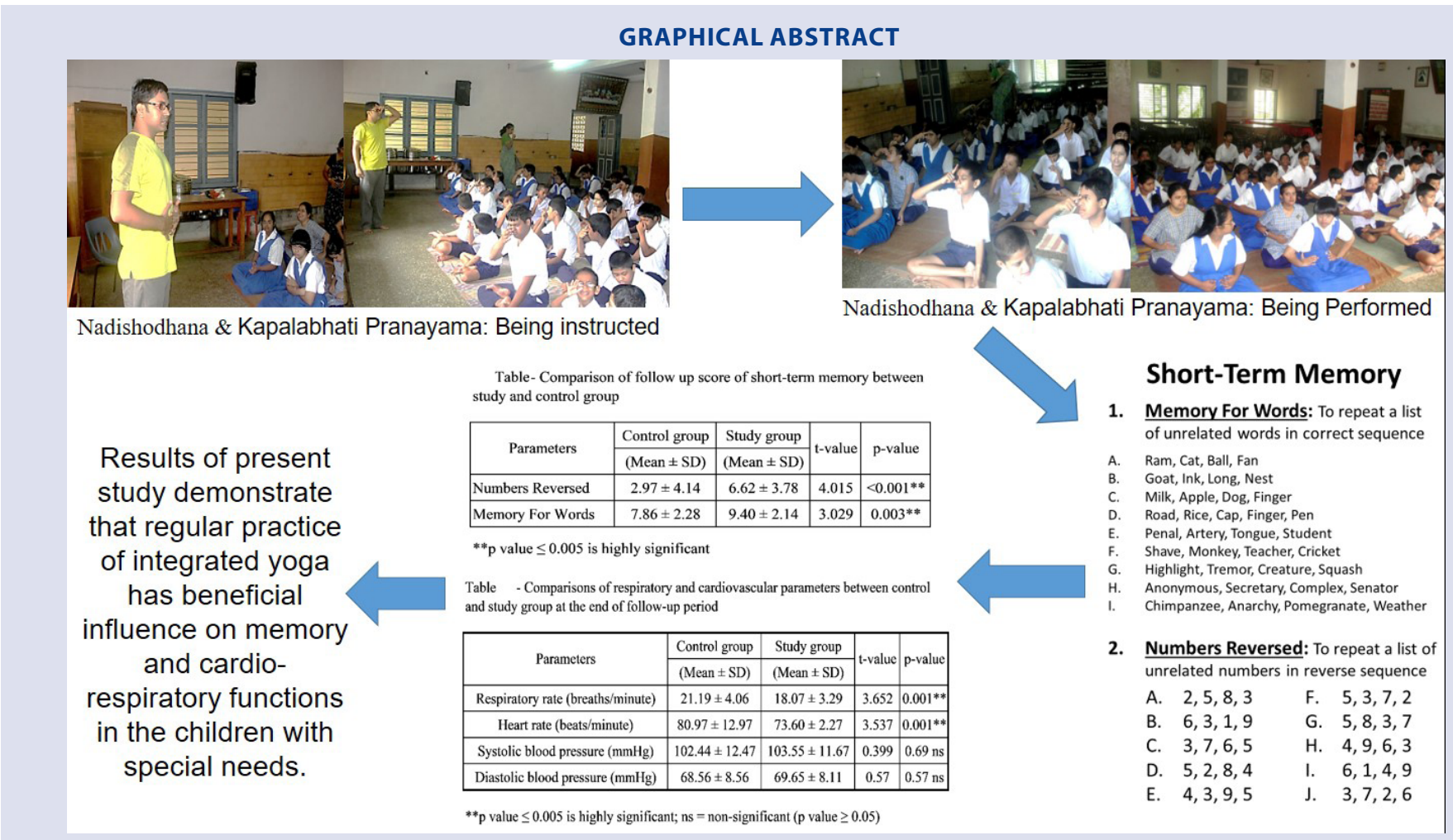

\section{SUMMARY}

- This study was aimed at evaluating the impact of 3 weeks integrated yogic practice of pranayama and meditation on cardio-respiratory functions and shortterm-memory (STM) in mentally challenged children. This was a randomized control trial involving 80 mentally challenged children attending a 'special school' at Mangalore, Karnataka. Study group comprised of 40 mentally challenged children and control group consisted of equal number of children, matched for chronological age, sex, waist-hip ratio, BMI, mental ability to that of the study group but did not take part in this integrated yoga training. Result of present study demonstrates that regular practice of integrated yoga has beneficial influence on memory and cardio respiratory functions in mentally retarded children.

\section{ABOUT AUTHORS}

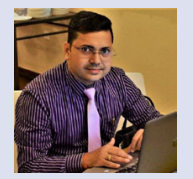

Dr. Kunal: He has obtained his MBBS and MD (Physiology) degree from Kasturba Medical College (KMC), Mangalore, Manipal Academy of Higher Education (MAHE). He did his "Tutorship" for 3 years in KMC, Mangalore and then worked for 4 years in Sikkim Manipal Institute of Medical sciences (SMIMS), Gangtok, Sikkim, SMU as Assistant Professor. Being in SMIMS he took care of various responsibilities, such as "Sports Chairman of SMU, Yoga trainer and In-charge of Yoga Lab, organised CME as Organising Secretary etc. He is currently working as Associate-Professor, Kasturba Medical College (KMC), Mangalore, Manipal Academy of Higher Education (MAHE), Karnataka, India. His field of interest is teaching, practicing and researching Yoga, Neuro, cardiovascular and pulmonary physiology. He has attended \& presented papers at various national \& international conferences, CME programs, Workshops, Faculty Development programs etc. He has received "The best paper award" at 23rd International Conference on Healthcare and Life-Science Research (ICHLSR), Dubai, UAE in the year 2017 for presenting this same paper.

Cite this article: Kunal, Subbalakshmi NK, Sheila PR, Shiva RK, Arunkumar N, Pai V, Chatterjee PK. Impact of Regularly Supervised Training of Pranayama and Omkar Meditation on the Cardio-Respiratory Parameters and Short-Term Memory of Persons with Special Needs. Pharmacog J. 2018;10(2):366-70. 